\title{
Effect of a periodic aerobic and anaerobic selective training with use of green tea on certain inflammatory factors and oxidative stress of male athletes
}

\author{
Naghmeh Naseri, Shahla Hojjat* and Asghar Khaledan \\ Department of Physical Education and Sport sciences, Islamic Azad University, Karaj Branch, Alborz, Iran
}

\section{ABSTRACT}

Due to the lack of complete information on the effects of aerobic and anaerobic exercises with taking supplements of green tea on malondialdehyde (MDA), creatine kinase, cortisol, this study was conducted to examine the effects of aerobic and anaerobic selective training (resistive) associated with the consumption of green tea on inflammatory factors and indicators of oxidative stress in male athletes of 20 to 35 years of age. In this study 60 male athletes were selected and randomly divided into 6 groups: Group A: aerobic exercise with green tea, Group B: aerobic exercise, group C: anaerobic exercise (resistive) with green tea, group D: anaerobic exercise (resistive), group E: only green tea and group $\mathrm{F}$ were conducted just their exercises (control).Results showed that doing aerobic exercises, anaerobic (resistive), aerobic and resistive exercise with green tea may increase MDA to effect on the number of oxidative stress and inflammation factors.

\section{KEY WORDS: GREEN TEA, ANAEROBIC EXERCISE (RESISTIVE), AEROBIC EXERCISE, OXIDATIVE STRESS, INFLAMMATION}

\section{INTRODUCTION}

Oxidative stress with damage to the kinds of cellular infrastructures reduces cell and physical function and muscle damage (Alok et al., 2003), (Anne et al., 2004), (Atalay et al., 2000). Some researchers believe that by adopting different strategies in order to inhibition of oxidative stress and lipid peroxidation and its reduction can be prevented from decline of sporty performance and even take step in improving it and increasing tolerance to exercise (Maria et al., 2003). Oxidative stress occurs when that creation of reactive species that are known as free radicals, in a system of ability of the system goes beyond to neutralization and removing these molecules (Bloomer, 2007), (Bloomer and Gold Farb, 2004). Since the oxidative stress during and looking to sport occurs only if the production of reactive oxygen species caused by sport goes beyond of the body's antioxidant potential capacity (Konig et al., 2001), (Radak et al., 2001).

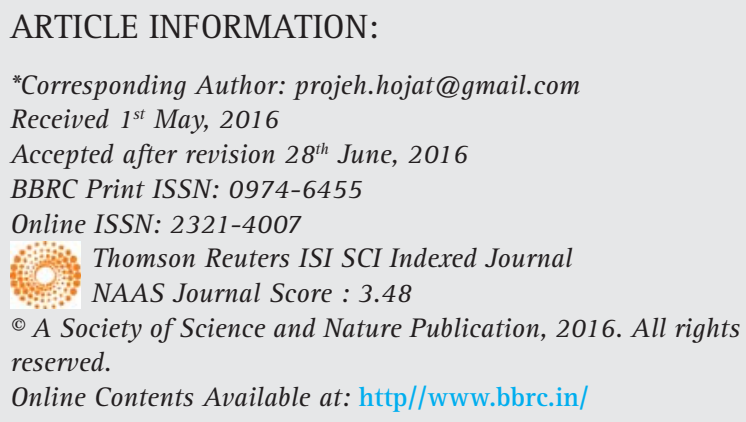


Green tea plant is cultivated and grown in Southeast Asia, including China, India, Japan, as well as in many African countries including South Africa (Luximo and Ramma, 2005). Tea leaves have medical consumption as well as aspect of the soda consumption in community. From 3 thousand years before Christ, traditional medicine of China have used green tea for headaches, body aches, ease of digestion, and increase in immunity defense power (safety), prevention of poisoning, and also an energizing substance, and causing lifetime (Ferrara et al., 2001). Green tea may prevent the oxidation of LDL cholesterol and thereby reduces the buildup of plaque in the arteries that thus improves cholesterol levels and cardiovascular health, and epigallocatechin - 3 - gallat (EGCG) prevents the activities of Metallo proteinases (MMPs), these have been implicated in the destruction of collagen and thus the effects of repression in cartilage damage in joints. Hence green tea may also reduce the severity of rheumatoid arthritis (Babitha et al., 2009). Among the most important group of antioxidants can be noted to flavonoids. As, green tea is an important source of flavonoids, it contains a group of polyphenolic flavonoids compounds called catechins and among the catechins, Epigallo catechin gallat (EGCG) are powerful antioxidants and the most common and most abundant polyphenols present in green tea (Murase et al., 2002).

Researchers in a study have confirmed the protective effect of green tea [(600 $\mathrm{ml}$ per day) 3 times per day, $200 \mathrm{ml}$ of boiling water with $2 \mathrm{~g}$ of dry green tea] in reducing lipid peroxidation during intense resistive exercise (Panza et al., 2008). In another study also have reported green tea can increase antioxidant capacity and reduces oxidative stress caused by strength exercises with intensity of 60\% (1RM) (Jowko et al., 2011). On the other hand (Call et al., 2008) in a research examined the endurance capacity of Maturity in mice MDX has increased by combining voluntary running with wheelchairs and green tea extract. The data show that every 2 of endurance training and green tea extract (GTE) as the therapeutic strategies for improving muscle performance may be useful in MDX mice. In another study (Jordan et al., 2007), they studied effects of green tea supplementation on the onset of muscle soreness and oxidative stress (oxidative stress), the workers have found that level of CK significantly increased at 24 hours after exercise.

But (Jowko et al., 2007) in a study performed by the effects of green tea extract Balance of reducing men oxidation exposed to intense strength exercises, specially muscle exercises) found these findings that muscle exercises prevents the Increasing caused by exercise in plasma CK activity and is decreased the activity of superoxide dismutase (SOD). While (Azizi et al., 2012) in his study found these results that oxidative stress of
ROS in the production of inflammatory cytokines caused by exercise is effective. Against the consumption of antioxidant supplement has effective role in reducing induced cytokine production caused by exercise. In this regard, (Nakhostin-Roohi et al., 2008) the effect of supplementation of vitamin C (1000 mg) were reviewed on lipid peroxidation, muscle damage and inflammation in 16 healthy male subjects with no exercise. The results showed a significant increase in MDA in the placebo group was 2 hours after exercise. CK also 24 hours after exercise had significant increasing in the placebo group. They showed consumption of vitamin C supplement prevents lipid peroxidation caused by sports and muscle damage.

Therefore, due to contradictory results obtained and the paucity of information in the field of green tea supplementation during aerobic and anaerobic activities (resistive) and its role on some inflammatory factors and indicator of oxidative stress in athlete subsequent of this type of exercises doing detailed studies and controlled has not been studied in this area, this study has been designed.

\section{MATERIAL AND METHODS}

The research methodology is type of semi experimental test. The statistical population were all male athletes of Tehran which by calling 100 people voluntarily (participating). That among these $(\mathrm{N}=100) 60$ people to purposefully (questionnaires) randomly selected as samples (simple) and were divided into 6 groups [5experimental groups ( $\mathrm{N}=50$ (and 1 control groups $(\mathrm{N}=10)$ ], (Ghasemi et al., 2012)

Including: Group A: Aerobic exercise with green tea Group B: Anaerobic exercise (resistive) with green tea. Group C: Just ate green tea, Group D: Only aerobic exercise, Group E: Just anaerobic exercise (resistance) and Group F: Just did their regular exercise (control). A week before the performing test measurements of height, weight, age and familiarity with the test methodology and receiving written consent were taken from the subjects. In addition, all subjects were in perfect physical and mental health and had no history of cardiovascular diseases, respiratory diseases and certain diseases. Before the starting from subject a pre-test and after finishing exercises, means after the 8 weeks was conducted a post-test. To 30 people of subjects was given $200 \mathrm{ml}$ of green tea ( $2 \mathrm{~g}$ of dry leave green tea in $200 \mathrm{ml}$ of water, $\left(100-80^{\circ} \mathrm{C}\right)$ as beverage (Panza et al., 2008) and 30 others subjects were without green tea. Blood test (fasting) was used for pretest and posttest. Exercises as 3 days on a week for 24 sessions means 8 weeks and its time was 60 minutes in each training session. 


\section{AEROBIC EXERCISE}

Aerobic exercises was doing aerobic exercises, which included 15 minutes of warm-up exercises (walking, softness movements, stretching movements, run and doing exercises by traction, barbell (light), ball, work on the steppe and perform a series of rhythmical movements that is 35 minutes and 10 minute cool-down that is total doing 60 minutes of aerobics that is for three sessions every other day on a week (3 days on a week) was intensity exercises between 65 to 75 percent of maximum heart rate. (Haghighi et al., 2012) (New aerobic exercises, kasten and Jordan, Volume 1) (Aerobics - education and its benefits, Veysi and Kashti dar, Volume 1)

\section{ANAEROBIC EXERCISE (RESISTIVE)}

Anaerobic exercise (resistive) that included a 10-minute warm up and then start to doing barbell training that includes 2 program as program for one to four weeks that includes 1 set and 8-12 repeat and 1-2 minutes resting.

\section{TAKING SUPPLEMENTS GREEN TEA}

In the groups that was considered taking supplement green tea the subjects were asked to maintain their diet for 8 weeks, 3 days per week the average $200 \mathrm{ml}$ of green tea $(2 \mathrm{~g}$ of dry leave green tea in $200 \mathrm{ml}$ water in temperature of $\left(80-100^{\circ} \mathrm{C}\right)$ is brewed and after exercises, were given to subjects as beverage

\section{BLOODLETTING AND MEASURING INDEXES OF RESEARCH}

Bloodletting after 12 to 14 hours fasting was performed in two stages of (before starting exercises means one day before starting the exercises, and after 8 weeks of exercise). In the first stage bloodletting that was done in Al-Nabie mosque gym bloodletting was carried out at $8 \mathrm{am}$ from subjects that the right hand vein of each subject in a sitting position ant at rest state was taken 5 $\mathrm{ml}$ of blood. In the second stage also after the 8 weeks also was done in the same way. To measure the cortisol, a serum from Monobind Company in wavelength of $45^{\circ} \mathrm{nmwas}$ used. Before starting doing work, all solutions, standards, controls and patient serum should be reached to 20 to $27^{\circ} \mathrm{C}$ of the room temperature. This way should be done by qualified personnel.

\section{METHODOLOGY INCLUDES OF THE FOLLOWING CASES}

To number of patients of Standard and control of Elisa microbes wells (wells within the micro plate as a square form) from kit that kept is kept at 2 to $8^{\circ} \mathrm{C}$, removed and for standard and controlling samples we pour 25 microliters in each well then $50 \mathrm{ml}$ of the cortisol's enzyme solution prepared added to each of microbes and mixed thoroughly and we shake 20 to 30 seconds. For measuring serum Malondialdehyde, Nanomol / $\mathrm{ml}$ in wavelength of $534^{\circ} \mathrm{nm}$ nanometers by UV-spectrophotometry device, spectrophotometric method (HPLC) was used.

The following two methods are used for measuring MDA:1.Spectrophotometry (TBARS)2. Method of (HPLC) / $532 \mathrm{~nm}$ 1.MDA in serum is separated by connecting with (TBA) and serum proteins are precipitated by TCA centrifugation. Then, TBA complex is measured at a wavelength of 534 nanometers. Necessary solutions include:1.TCA solution 17.5 percent 2. TCA solution 70 percent 3. TBA solution 0.6 percent. Test methodology is as follows:

Calculation of Results: The concentration of MDA in $\mathrm{nmol} / \mathrm{ml}$ is calculated by the following formula:

$$
\frac{\text { Abs (test) }}{1 / 56 \times 10^{5} 1 / 56 \times 10^{5}}-\text { Abs blank }
$$

Method of HPLC after sample preparation for measuring MDA prepared solution by syringe for the device of HPLC injected and in wavelength of $532 \mathrm{~nm}$ in standard of determined concentration of MDA and MDA we obtain samples by using the standard curve (AL -Anee et al., 2009).

\section{WAY OF MEASURING THE CREATINE KINASE}

For measuring creatine kinase (CK - MB), micro liter in $340^{\circ} \mathrm{nm}$ wavelength with the Cubas auto analyzer device and photometric method was used.

Method: (DGKC), (Deutsche Gesellschaft für clinical chemistry (DGKC) and (IFCC), [InternationalFederation of clinical chemistry (IFCC)]. Test methodology: wavelength: 340 nanometers, cuvette diameter: one centimeter, temperature $37^{\circ} \mathrm{C}$, and measurement: photometer with Blank consumption is set to zero. (Stein et al., 1998), (Moss et al., 1999), (Ürzburg et al., 1977).

\section{STATISTICAL METHODS}

For recognizing and naturalization of data, Kolmogorov and Smirnov test has been used and it was identified that groups are not different from each other. Descriptive statistics was used in order to calculating central indexes and dispersion was used. Inferential statistics was used for unilateral variance analysis statistical test and tukey post hoc test. Significance level was considered as alpha 0.05. All statistical operations were done through SPSS software version 20. 


\section{RESULTS AND DISCUSSION}

First hypothesis: Part I: Investigating effect of aerobic exercise and green tea on the three variables of MDA, CK and CORT Null hypothesis: Aerobic exercise along with green tea has no significant impact on the amount of MDA of male athletes of 20 to 35 years old.

The results of one-way variance analysis test for comparison of the amount of changes in plasma resting MDA did not show a significant difference between changes in four groups of aerobic exercise along with green tea, aerobic exercise, green tea, and control $\left(\mathrm{F}_{3,36}\right.$ $=1.124$, Sig $=0.352$ ) Table 1 shows one-way variance analysis test results for comparison of the amount of changes in plasma resting MDA in four groups of aerobic exercise along with green tea, aerobic exercise, green tea, and control.

\section{SECOND HYPOTHESIS}

Null hypothesis: Aerobic exercise along with green tea has no significant impact on the amount of CK of male athletes of 20 to 35 years old.

The results of one-way variance analysis test for comparison of the amount of changes in plasma resting CK did not show a significant difference between changes in four groups of aerobic exercise along with green tea, aerobic exercise, green tea, and control $\left(\mathrm{F}_{3,36}\right.$ $=3.417, \mathrm{Sig}=0.027)$ Table 2 shows one-way variance analysis test results for comparison of the amount of changes in plasma resting CK in four groups of aerobic exercise along with green tea, aerobic exercise, green tea, and control.

\section{THIRD HYPOTHESIS}

Null hypothesis: Aerobic exercise along with green tea has no significant impact on the amount of CORT of male athletes of 20 to 35 years old.

The results of one-way variance analysis test for comparison of the amount of changes in plasma resting CORT did not show a significant difference between changes in four groups of aerobic exercise along with green tea, aerobic exercise, green tea, and control $\left(\mathrm{F}_{3,36}\right.$ $=0.721$, Sig $=0.546$ ) Table 3 shows one-way variance analysis test results for comparison of the amount of changes in resting CORT in four groups of aerobic exercise along with green tea, aerobic exercise, green tea, and control.

\section{PART II: INVESTIGATION THE EFFECT OF AEROBIC EXERCISE (RESISTANCE) AND GREEN TEA ON THREE VARIABLES OF MDA, CK AND CORT}

Forth hypothesis : Null hypothesis:Resistive exercise along with green tea has no significant impact on the amount of MDA of male athletes of 20 to 35 years old.

\begin{tabular}{|l|l|l|l|l|l|}
\hline \multicolumn{7}{|l|}{ Table 1: Test Results One way ANOVA for amount of resting } \\
plasma MDA changes of four groups of research \\
\hline & Sum of squares & d & Mean Square & F & Sig \\
\hline Intergroup & 0.154 & 3 & 0.051 & 1.124 & 0.352 \\
\hline Within group & 1.648 & 36 & 0.046 & & \\
\hline Total & 1.803 & 39 & & & \\
\hline
\end{tabular}

Table 2: one-way variance analysis test results for the amount of changes in plasma resting CK in four study groups

\begin{tabular}{|l|l|l|l|l|l|}
\hline & Sum of squares & D & Mean Square & F & Sig \\
\hline Intergroup & 90.1749 & 3 & 583.30 & 3.417 & 0.027 \\
\hline Within group & 00.6146 & 36 & 170.72 & & \\
\hline Total & 90.7895 & 39 & & & \\
\hline
\end{tabular}

Table 3: one-way variance analysis test results for the amount of changes in plasma resting CORT in four study groups

\begin{tabular}{|l|l|l|l|l|l|}
\hline & Sum of squares & d & Mean Square & F & Sig \\
\hline Intergroup & 148.51 & 3 & 17.49 & 0.721 & 0.546 \\
\hline Within group & 828.850 & 36 & 23.634 & & \\
\hline Total & 976.901 & 39 & & & \\
\hline
\end{tabular}


The results of one-way variance analysis test for comparison of the amount of changes in plasma resting MDA showed a significant difference between changes in four groups of resistive exercise along with green tea, resistive exercise, green tea, and control $\left(\mathrm{F}_{3,18.86}=\right.$ 3.276 , Sig $=0.044$ )(There was no homogeneity of variance between forth groups, so Welch amendment has been done). Table 4 shows one-way variance analysis test results for comparison of the amount of changes in resting MDA in four groups of resistive exercise along with green tea, resistive exercise, green tea, and control.

\section{FIFTH HYPOTHESIS}

Null hypothesis:Resistive exercise along with green tea has no significant impact on the amount of CK of male athletes of 20 to 35 years old.

The results of one-way variance analysis test for comparison of the amount of changes in plasma resting CK showed a significant difference between changes in four groups of resistive exercise along with green tea, resistive exercise, green tea, and control $\left(\mathrm{F}_{3,36}=4.132\right.$, $\mathrm{Sig}=0.013$ ). Table 5 shows one-way variance analysis test results for comparison of the amount of changes in resting $\mathrm{CK}$ in four groups of resistive exercise along with green tea, resistive exercise, green tea, and control.

\section{SIXTH HYPOTHESIS}

Null hypothesis: Resistive exercise along with green tea has no significant impact on the amount of CORT of male athletes of 20 to 35 years old. The results of one-way variance analysis test for comparison of the amount of changes in plasma resting CORT showed a significant difference between changes in four groups of resistiveexercise along with green tea, resistive exercise, green tea, and control $\left(\mathrm{F}_{3,36}=8.301, \mathrm{Sig}=0.000\right)$. Table 6 shows one-way variance analysis test results for comparison of the amount of changes in resting CORT in four groups of resistive exercise along with green tea, resistive exercise, green tea, and control.

\section{PART III: COMPARISON OF THE EFFECT OF AEROBIC EXERCISE AND ANAEROBIC (RESISTANCE) AND GREEN TEA ON THREE VARIABLES OF MDA, CK AND CORT}

Seventh hypothesis: Null hypothesis: There is no significant difference between the impact of aerobic exercise along with green tea, and between resistive exercise along with green tea, and green tea on the MDA of male athletes of 20 to 35 years old. The results of one-way variance analysis test for comparison of the amount of changes in plasma resting MDA did not show a significant difference between changes in six study groups $\left(\mathrm{F}_{5,24.28}=2.256\right.$, Sig $\left.=0.081\right)$ (there was no homogeneity of variance between four groups, so Welch amendment has been done). Table 7 shows the results of oneway variance analysis test results for comparison of the amount of changes in plasma resting MDA in six study groups.

\begin{tabular}{l} 
Table 4: one-way variance analysis test results for the \\
amount of changes in plasma resting MDA in four study \\
groups \\
\hline
\end{tabular}

\begin{tabular}{|c|c|c|c|c|c|}
\hline & Sum of squares & d & Mean Square & $\mathrm{F}$ & Sig \\
\hline Intergroup & 1558.70 & 3 & 519.57 & 4.132 & 0.013 \\
\hline Within group & 4526.40 & 36 & 125.73 & & \\
\hline Total & 6085.10 & 39 & & & \\
\hline
\end{tabular}

\begin{tabular}{|c|c|c|c|c|c|}
\hline & Sum of squares & $\mathrm{D}$ & Mean Square & $\mathrm{F}$ & Sig \\
\hline Intergroup & 885.817 & 3 & 295.27 & 8.301 & 0.000 \\
\hline Within group & 1280.593 & 36 & 35.57 & & \\
\hline Total & 2166.410 & 39 & & & \\
\hline
\end{tabular}




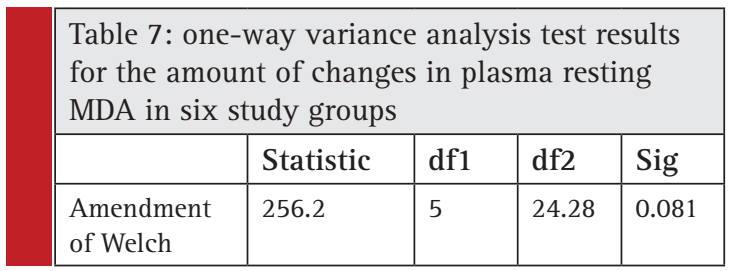

Table 8: one-way variance analysis test results for the amount of changes in plasma resting CK in six study groups

\begin{tabular}{|l|l|l|l|l|}
\hline & Statistic & df1 & df2 & Sig \\
\hline $\begin{array}{l}\text { Amendment } \\
\text { of Welch }\end{array}$ & 098.4 & 5 & 24.77 & 0.008 \\
\hline
\end{tabular}

\section{EIGHTH HYPOTHESIS}

Null hypothesis: There is no significant difference between the impact of aerobic exercise along with green tea, and between resistive exercise along with green tea, and green tea on CK of male athletes of 20 to 35 years old.

The results of one-way variance analysis test for comparison of the amount of changes in plasma resting CK showed $l_{F 5,24.77}=4.098, \mathrm{Sig}=0.008$ ) (there was no variance homogeneity between four groups, so Welch amendment has been done). Table 8 shows the results of one-way variance analysis test results for comparison of the amount of changes in plasma resting CK in six study groups.

\section{NINTH HYPOTHESIS}

Null hypothesis: There is no significant difference between the impact of aerobic exercise along with green tea, and between resistive exercise along with green tea, and green tea on CORT of male athletes of 20 to 35 years old. The results of one-way variance analysis test for comparison of the amount of changes in plasma resting CORT showed a significant difference between changes in six study groups $\left(\mathrm{F}_{5,24}=7.172\right.$, Sig $\left.=0.000\right)$. Table 9 shows the results of one-way variance analysis test results for comparison of the amount of changes in plasma resting CORT in six study groups.

The present study showed that doing aerobic, anaerobic (resistance) exercise, and aerobic and resistance exercise along with green tea may increase MDA and affect some factors of oxidative stress and inflammatory. Researchers believe that although different cells and textures of body produce free radicals as a part of metabolism but sometimes such as during work and physical activity, producing these radical species will go beyond body's antioxidant capacity and will lead to oxidative stress (Bloomer et al, 2005). Green tea as a strong antioxidant supplementary paly and effective role in neutralization free radicals and increasing the capacity of body's antioxidant system and reducing lipid peroxidation (Kuriyama et al, 2008) and (Yuan et al, 2011).

In extreme resistance exercises, the process of ischemia and reperfusion and mechanical loads exerted on the involved soft tissues have effective role in the creation of lipid peroxidation and the production of free radicals (Dixon et al, 2006). During exercise diversion of blood to the skin and active muscles cause transient tissue hypoxia and lack of coordination of active oxygen consumption and oxygen requirements in the active textures during high intensity exercise; although following re-oxygenating of these textures and cutting off or reducing the intensity of activity, producing reactive oxygen species (ROS) will be provided with increasing lipid peroxidation and cell function decline (Ogonovszky et al, 2005) and (Watson et al, 2005). Catechins found in green tea can increase the capacity of antioxidant through increasing intracellular antioxidant such as glutathione, uric acid and bilirubin and increasing the capacity of intracellular antioxidant enzymes such as glutathione reductase and glutathione peroxidase and catalase in protecting cell against depletion of reduced glutathione and by this mechanism help increasing TAC (Raihan et al, 2009).

Generally these compounds because of having hydroxyl groups can neutralize free radicals and can act as the electron or hydrogen donor (Katiyar et al, 2007). Catechins found in green tea especially (EGCG) may inhibit the process of lipid peroxidation through reducing the production of free radicals (mainly because of having dihydroxy phenol structure) as well as reconstruction of tocopherol (converting tocopherol to tocopherol radical). Through connecting copper element and preventing connecting this element to lipoproteins, Catechins can significantly prevent reducing tocopherol

\begin{tabular}{|c|c|c|c|c|c|}
\hline & Sum of squares & D & Mean Square & $\mathrm{F}$ & Sig \\
\hline Intergroup & 1094.021 & 5 & 218.804 & 4.172 & 0.000 \\
\hline Within group & 1647.365 & 54 & 30.507 & & \\
\hline Total & 2741.386 & 59 & & & \\
\hline
\end{tabular}


concentrations in plasma and cause a delay in beginning the process of plasma lipid peroxidation. (Ostrowska et al, 2006).

Recently, Ghasemi et al, (2013) have reported the consumption of green tea for 14 days as the reason for increasing TAC significantly and significant decrease of MDA by intense resistance activity with the strength of 85\% (RM1) in health non-athlete women and also in a research that (Alkhamees et al, 2013) did, they found out that through using Moran consumption [Portugal Osage], (15 and 30 milligram/kilogram/day) for five weeks that with Moran treatment (Portugal Osage: The most potent flavonoid inhibitor is fatty acid synthesis) in diabetic mice respectively after reducing MDA and increasing the levels of DNA,T-GSH and increasing the activity SOD in liver cells decreased oxidative stress induced by STZ significantly. These biochemical findings were similar to the confurmations of histopathologic changes. But (Swamy et al, 2011) had noticed in their obtained results that rats fed by polyphenols showed important increase during swimming and increased the activities of lactate dehydrogenase (LDH) and Creatine and also decreased the value of MDA in liver, muscles and blood but the concentration of DNA and RNA will be increased by this in muscles.

The reasons of these disagreements may be because of supplements, exercise, exercise intensity, samples (healthy or patient human or animal model) and gender (male or female) because on the contrary of (Alkihamees et al, 2013), in current study the type of supplementary has been green tea and considering misalignment (Ghasemi et al, 2012), in current findings the type of done exercise has been aerobic exercise and intensity aerobic exercise 65 to 75 percent of maximum heart rate and on the contrary of (Swamy et al, 2011) in current research, it can be said that all participants were healthy athlete men. The researches have also showed that Malondialdehyde is a secondary product of lipid peroxidation that is measured as the index of oxidative stress (Ghasemi et al, 2012) and final product of oxidation of lipid peroxidase is in lipid membrane of cells in the body that inflammation processes have been increased there and in case of neutralization by body's respiratory system can damage structure and function of cell membranes of the body (Devasagayam et al, 2004) and (Nielsen et al, 1997).

We have some evidences out of recent researches that intensive physical activity not only long-term aerobically but also in short-term anaerobic may stimulate oxidative stress (Alessioet al, 2000). It was assumed that oxidative stress more likely will help the fatigue and damaging muscle cells and as result it may affect sport performance (Watson et al, 2005). One of the effects of oxidative stress is intensification of lipid peroxidation which is reflected by increasing blood concentration with its products that is Hydroxy fatty peroxidase (LOOH), MDa as well as Thiobarbituric substances with acid reactive (TBARS) (Davies et al, 1982). In done researches by (MC Bride et al, 1998), intense resistance training stimulates increasing in MDA concentration in blood which in higher level before exercise was maintained even till 24 hours. Most of researches have also showed that one level of boring exercise or intensive sport activity or in long period cause increasing the index of oxidative stress (MDA) and decreasing the capacity of total serum antioxidant (Tauler et al, 2006) and (Jafari et al, 2011).

In spite of this, one hand available oxygen increase production of free radicals and along intensive physical activities which we face increasing consuming oxygen their producing will reach to several times of the resting mode (Tauler et al, 2006), Malondialdehyde or MDA as a free radical is a deformation of hydrogen peroxide (H202) that is effective on creation of conditions of oxidative stress and blood, MDA of tissue damage (Tauler et al, 2006). Increasing the concentration of MDA in blood is also dependent on the intensity of sport and whatever the intensity of activity is more, production and releasing MDA will increase as well (Valado et al, 2007).

Considering that one of the very likely mechanisms involved in cell damage is increasing leakage of free radicals and oxidative stress caused by them, Malondialdehyde index which represents the value of lipid peroxidation (Cell membrane lipid oxidative damage), it was investigated as possible mechanisms involved in causing harm (Chiaradia et al, 1998) and (FrankiewiczJozko et al, 1996). Also considering that glutamine is the precursor of glutathione so glutathione can decrease lipid peroxidation and free radicals through increasing the capacity of plasma antioxidant (Cotgreave et al, 1998). On the other hand the reaction of free radicals with cells skin will lead to produce one of the stress indexes that provide the possibility of measuring oxidative stress indirectly by an oxidative called Malondialdehyde ,( Bride et al, 1999). Considering the implemented researches, it can be said that other factors related to type of exercise, sports field, exercise intensity, exercise duration, type of training, supplements, supplementation dose, gender, samples (human or animal model) and other factors can also be effective on decreasing or increasing MDA.

\section{REFERENCES}

Eddington and Edgeron, (1994), Physical activity biology, translator Hojatolah Nikbakht, first printing, Samt publishing.

Lee Brown, the first / (2012), planned reference book of strength training: physiology knowledge, power and weight 
training systems / [National Association of strength and fitness the United States, B. Nowshadi, release the ball first.

Casten Carroll, Jordan Peg, first / (2010), the new practice aerobics, F. Masoudi in collaboration with Loretta Vdysyan, publisher of movement, first.

Veisi Koroosh, Keshtidar M., II / (2010), aerobics - education and its benefits, publications Bamdadktab, first.

Haghighi Ah (2012), the effect of aerobic training and green tea supplementation on serum leptin levels and insulin resistance in overweight and obese men, Journal of Sport Biosciences, No. 15, pp. 43-23.

Haghverdi, Farshid, (2002), Evaluation of liver enzymes in patients with diabetes in Tajrish Shohada hospital, Shahid Beheshti University of Medical Sciences thesis.

Hamzezadeh Boroujeni E., (2013), the effect of 4-week intensive interval exercise (HIT) on the levels of IGF-1, GH, IGFBP-3 and cortisol of women's serum of national basketball team, exercise physiology, Issue 19, Page 158 - 143.

Ghasemi, E. (2012), the impact of a morning and evening peak aerobic exercise on plasma levels of growth hormone and cortisol in young women, motor sports and Life Sciences, Volume 3, Number 1, (row 5).

Ghasemi Elham (2013), Short-term effects of green tea supplementation on total antioxidant capacity and lipid peroxidation of young women after a severe resistance training session, Journal of Medical School, No. 202, 30th year.

Talebi Gorgani E., (2001), The effect of two different regimes of vitamin $\mathrm{C}$ on delayed onset muscle soreness after intense eccentric contraction, Thesis (MA) University of Guilan, Faculty of Physical Education and Sport Sciences.

Azizi M. (2012), inflammatory indices (IL-6, TNF- $\alpha$ ), oxidative (MDA) and muscle damage after swimming and use of vitamin-mineral supplements, exercise physiology, Number 13, pp. 62-47.

Alessio, H.M., A.E.Hagerman, (2000), Generation of reactive oxygen species after exhaustive aerobic and isometric exercise, Medicine and science in sports and Exercise, 32(9), 1576-1581.

Alok K. Banerjee, Amritlat Mandal, (2003), Dipanjan chanda and sajal chakraborti. Oxidant, antioxidant and physical exercise, Molecular and cellular Biochemistry, 253: PP: 307 - 312.

Anne-Sophie Rousseau (2004), Antioxidant vitamin status in high exposure to oxidative stress in competitive athlete, British Journal of Nutrition, 92, PP: 261 - 468.

Atalay M., Laakksonen D.E.Khanna (2000), Vitamin E regulates change in tissue antioxidants induced by fish oil and acute exercise, Med.Sci. Sport exerc: 32 (3) .PP: 601-607.

Al-Anee.Ahmed H, Shihab.salam, Edan.Hazim H, Aljanabee. Jasim, (2009), Evaluation of serum malondialdehyde in relation to other clinical considerations in premature neonates, Tikrit Medical Journal, 15 (2): 42- 51.

Alkhamees.Osma, (2013), Morin aflavonoid exerts antioxidant potential in streptozoto-cin induced hepatotoxicity. British Journal of pharmacology and toxicology, 4 (1): 10 - 17.
Arent.Shawn M, Senso.Mehan, Golem.Devonl, (2010), The effects of theaflavin-enriched black tea extract on muscle soreness, oxidative stress, inflammation, andendocrin responses to acute anaerobic interval training:a randomized, double -blind,crossover study, Journal of the international society of sports nutrition, 7:11.

Arent.SM, Davitt.P, Golem.D L, (2010), The effect of a postworkout nutraceutical drink on body composition,performance and hormonal and biochemical respanses in division I college football players,comparative physic- ology 6 (2);73-80, Journal of strength and conditioning research, volume 24 . Number 4.

Azimi.Bita, Mehrabani.javad, Damirchi.Arsalan, Elmieh.Reza, kherandish Mehrzad. (2011), Intraction effect of six weeks exercise training and green tea on cardiovascular risk factors in sedentary young women, 1.Guilan university 2. Islamic azad university rasht branch, Electronic physicion, volume3(3), Iran, 15-16.

Bloomer R.J, A.C.Fry, (2007), Protein carbonyls are acutely elevated following singleset anaerobic exercise in resistance trained men, J sci Med sport, 10 (6): 411-7.

Bloomer R.J, Gold Farb AH.Mckenzie MJ, You T, Nguyen L (2004), Effect of antioxidant therapy in women exposed to eccentric exercise, Int J sport Nutr Exerc Metab, 14 (4): 377-88.

Bloomer, R.J, A.H. Gold Farb (2005), Effect of acute aerobic and anaerobic exercise on blood markers of oxidative stress. J Strength Cond Res, 19(2):276 - 85.

Burtis CA, Ash Wood ER. (2001), Clinical chemistry. 5th.philadelphia Saunders Company. Pp: 356 - 7.

Basta.P, Pilaczynska-Szczesniak.L, Woitas-Slubowska D. (2013), Influence of aloe arborescence mill. Extract on selected parameters of prooxidan-antioxidant Equilibrium and cytokine synthesis in Rowers.Int J sport Nutr Exerc.

Babitha.N, D.N.Swamy, Swarna Chakrapani. (2009), Role of green tea as an antioxidant in periodontal disease. Journal of Orofac.scie.1 (2): 39 - 42.

Bonina F.P., Puglia C., Cimino F. (2005), Oxidative stress in hand ball players:effect of supplementation wite a red orange extract, Nutrition Research, 25:917 - 924.

Call.Jordan A, Voelker.kevin A, Wolff.Andrew V, et al. (2008), Endurance capacity in maturing $\mathrm{mdx}$ mice is markedly enhanced by combined voluntary wheel running and green tea extract, J Appl physiol 105: 923 - 932.

Costa.Camilas.C.DA, Palma.Alexandre, Pedrosa.Cristiana M. (2012), Female futsal players profileand biochemical alterations through intermittent High-intensity exercise training, Food and Nutrition sciences, 3, 110 - 116.

Cho M. (2004), The strength of motivation and physical activity level during leisure time among youth in South Korea Youth and society, 32 - 35.

Cotgreave IA, Gerdes RG. (1998), Recent trends in glutathione biochemistry glutathione-protein interactions: a molecular link between oxidative stress and cell proliferation? Biochem Biophys Res Commun, 242 (1): 1 - 9. 
Chiaradia E, Avellini L, Rueca F, Spaterna A, Porciello F, Antonioni MT. (1998), Physical exercise, oxidative stress and muscle damage in racehorses. Comp Biochem Physiol B Biochem Mol Biol, 119 (4); PP: 833 - 6.

Cheung K, Hume P, Maxwell L. (2003), Delayed onset of muscle soreness: treatment strategies and performance factors. Sports Med, 33(2):145 - 6 .

Clarkson PM, Kroll W, Graves J, Record WA. (1982), The relationship of serum creatin kinase, fiber type and isometric exercise. Int J Sports Med, 3:145 - 6.

Chacko SM, Thambi PT, Kuttan R, et al. (2010), Benefical effects of green tea:aliterature review. Chinese Medicine, 5:13.

Dixon, C.B, Robertson, RJ., Goss, F.L., Timmer, J.M., Nagle, E., Evans, R.W, (2003), Effect of resistance training status on free radical production and muscle damage following acute exercise. [D-140 free communication/slide skeletal muscle injury and repair]. Med \& sci in sports Exe. 35(5) supplement 1PS 157.

Delfan B. (2013), the effect of aerobic and anaerobic exercises on anxiety and hormones cortisol secretion and the young wrestlers blood, Journal - Lorestan University of Medical Sciences, Volume XV, Number 3, Number 56.

Dixon CB, Robertson RJ, Goss FL, (2006), The effect of acute resistance exercise on serum malondialdehyde in resistance trained and untrained collegiate men. J Strength Cond Res; 20 (3): 693-8.

Dufou R, Lott JA, Henry JB, (2001), Clinical enzymology. In: Henry JB. Clini- cal diagnosis and management by labrotoary methods. 20th. Philadelphia: saund- ers company, pp: 292-300.

Davydov VV, Shvets VN. (1999), Different changes in the cytosole creatin- kinase isoenzymes from heart of adult and old rats during stress. EXP Gerontol. Nov; 34 (7): 885 - 8.

Devasagayam TP, Tilak JC, Boloor KK, (2004), Free radicals and antioxidants in human health: current status and future prospects. J Assoc physicians India; 52: 794-804.

Davies K.J.A., Quintanilha A.T., Brooks G.A., et al. (1982), Free radicals and tissue damage produced by exercise. Biochemical and Biophysical Research communications, 1982, 107: 1198 1204.

Erba D., Riso P., Bordoni A., (2005), Effectiveness of moderate green tea consumption on antioxidative status and plasma lipid profile in humans. Journal of Nutritional Biochemistry, 16:144 - 149 .

Foster L, Dunn R, (1974), Single anti body technique for radio immunoassay of cortisol in unextracted serum or plasma, Clin Chem, 20, 365.

Ferrara, L.Montesano, D.and Senator, A, (2001), The distribution of minerals and flavoids in the tea plant (Camellia sinensis) .IL Farmaco, 56: 397 - 401.

Frankiewicz-Jozko A, J Faff, and B Sieradzan-Gabelsks, (1996), Changes I concentrations of tissue free radical marker and serum creatinekinase during the postexercise period in rats. Eur J Appl Physiol, 74; PP: 470 - 474.
Jafari A, Zekri R, Dehghan G, Malekirad AA, (2011), Effect of short-term garlic extract supplementation on oxidative stress and inflammatory indices in non-athlete men after an aerobic exercise.JCT, 2:23 - 31.

Jokwo E, Sacharuk J, Balasinska B, Ostaszewski P. (2011), Green tea extract supplementation gives protection against exercise-induced oxidative damage in healthy men. Nutr Res, 31 (11): 813 - 21 .

Jowko.EWA, Sacharuk.Jaroslaw, Balasinska.Bozena (2012), Effect of a single dose of green tea polyphenols on the blood markers of exercise-induced oxidative stress in soccer players, International Journal of sport Nutritional and exercise metabolism, 22, 486 - 496.

Jowko.EWA, Sacharuk.Jaroslaw, Balasinska.Bozena, (2007), Effect of green tea extract on the oxidation-reduction balance in men exposed to intensive strength exercise, studies in physical culture and tourism, vol.14.

Jordan.Shanon lynn, Sawyer.Robert D, Williams.James S, Carter.Rick, (2007), The effects of green tea extract supplementation on delayed on set muscle soreness and oxidative stress.

Kuriyama S. (2008), The relation between green tea consumption and cardiovascular disease as evidenced by epidemiological studies. J Nutr; 138(8): 1548 - 53.

Katiyar S, Elmets CA, Katiyar SK. (2007), Green tea and skin cancer: photoimmunology, angiogenesis and DNA repair. J Nutr Biochem; 18 (5): 287 - 96.

Konig D.Wagnerk-H., Elmadfa I, et al. (2001), Exercise and oxidative stress: significant of antioxidants with reference to inflammatory, muscular and syste- mic stress. Exercise immunology review, 7; pp 108 - 133.

Luximo-Ramma, A., Bahorun, T., Crozier, A., Zbarsky, V. (2005), Characterization of the antioxidant functions of flavonoids and proanthocyani- dis in maurition black teas. Food Research International, 38: 357 - 367.

Mcanulty S.R., MC Anulty l.s., Nieman D.C. (2004), Consumption of blueberry polyphenols reduces exercise-induced oxidative stress compared to vitamin C, Nutrition Research, 24,pp:209 - 221.

Maria L.Urso, Priscilla M.Clarkson, (2003), Oxidative stress, exercise, and antioxidant supplementation. Toxicology, 189; pp: $41-45$.

Moss DW, Henderson AR. (1999), Clinical enzymology.In: Burti CA, Ashwood ER, edit-ors. Tietz Text book of clinical chemistry. 3rd ed. philadelphia: W.B Saunders company.617 - 721.

Murase T, Nagasawa A. (2002), Beneficial effects of tea catechins on diet-induced obesity: stimulation of lipid catabolism in the liver. International Journal obesity related metabolic disorder, 26: pp: 1459 - 1464.

MC Bride J.M., Kraemer W.J. (1998), Effect of resistance exercise on free radical production, medicine and science in sports and exercise, 30 (1), pp 67 - 72.

MC Bride JM, Kraemer WJ. (1999). Free radicals, exercise, and antioxidants .Strength And Conditioning Research.13: PP: 175-183. 
Mirzaghbik H., H Sade Hashim J (2001), investigating an exercise session until exhaustion on testosterone and cortisol serum and ratio of testosterone to cortisol of elite basketball players, MA thesis, Tehran University, Faculty of Physical Education.

Nakhostin-Roohi B, Babaei P, Rammani-Nia F, Bohloolis, (2008), Effect of vitamin C supplementation on lipid peroxidation, muscle damage and inflamm-ation after 30-min exercise at 75\% V02max. J Sports Med Phys Fitness, 48 (2): 217 - 24.

Nielsen F, Mikkelsen BB, (1997), Plasma malondialdehyde as biomarker for oxidative stress: Reference interval and effects of life-style factors. Clin chem, 43 (7): 1209 - 14.

Ogonovszky H, Berkes I, Kumagai S. (2005), The effects of moderate-, strenuous - and over - training on oxidative stress markers, DNA repair, and memory, in rat brain. Neurochem Int; 46 (8): 635 - 40.

Ostrowska J, Skrzydlewska E. (2006), The comparison of effect of catechins and green tea extract on oxidative modification of LDL in vitro. Adv Med Sci; 51: 298 - 303.

OZ.Helieh S, Chen.Theresa and, De Villiers.Willem J.S, (2013), Green tea polyphenols and sulfasalazine have parallel antinflammatory propertiesin colitis models, June, volume 4, article 132, 1 - 10, Frontiers in Immunology.

Ozkol.Halil, Koyuncu.Ismail, Tuluce.Yasin, (2011), Some medicinal plants counteract alterations of neuroendocrine stress response system,oxidative and nitrosative stress caused by repeated restraint inrats, Journal of Medicinal plants research, vol.5(17), pp.4360-4368, 9 september, ISSN 1996 0875.

Ormsbee.Michael J, Kinsey.Amber W, Chong.Minwook (2013), The influence of high intensity interval training on the salivary cortisol response to ap psychological stress or and mood state in non-sedentary college students, Journal of exercise physiology, volume 16, Number 1.

Panza, V.S.P., Wazlawik, E., Schütz, G.R., Comin, L., Hecht, K.C., et al. (2008), Consumption of green tea favorably affects oxidative stress markers in weight-trained men.Nutrition, 24 (5), 433-442.pub Med doi: 10.1016 / j. nut. 2008. 01. 09.

Radak Z., Taylor A.W., Ohono H., Goto.S, (2001), Adaptation to exercise induce oxidative stress.from muscle tobrain. Exercise immunology review, 7: pp:90 - 107.
Raihan SZ, Chowdhury AK, Rabbani GH.(2009), Effect of aqueous extracts of black and green teas in arsenic - induced toxicity in rabbits. Phytother Res, 23 (11): 1603 - 8.

Stein W, (1998), Creatinekinase (total activity), creatinkinase isoenzymes and variants. In:Thomas L,ed.clinical laboratory diagnostics.Frank furt:TH-Book Verlagsges-ellschaft. p.71 - 80.

Swamy.Mahadevappa siddalinga, Sivanna.Naveen, Tamatam. Anand, et al. (2011), Effect of polyphenols in enhancing the swimming capacity of Rats, Functional Food in health and Disease, 1(11):482 - 491.

Tauler P, Sureda A, Cases N. (2006), In creased lymphocyte antioxidant defences in response to exhaustive exercise do not prevent oxidative damage. J Nutr Biochem, 17(10):665 - 671.

Trivic.Tatjana, Drid.Patrik, Obadov.Slavko (2011), Effect of endurance training on biomarkers of oxidative stress in male wrestlers, I do movement for culture. jour- nal of martial artsanthropology, vol.11.no.2 (2011), pp.6 - 9.

Valado A, Pereira L, Paula C, et al. (2007), Effect of the intense anaerobic exercise on nitric oxide and malondialdehyde in studies of oxidative stress. J Biol Biomed Engineer, 1 (1): $78-82$.

Watson TA, MacDonald - Wicks LK, Gatg ML, (2005), Oxidative stress and antioxidants in athletes Nutr Exerc Metab; 15 (2): $131-46$.

Wuly, Juan CC, Maen K., (2004), Green tea supplementation ameliorates insulin resistance and increases glucose transporter IV content in a fructose-fed rat model. European journal of nutrition, 43:pp:116 - 124 .

Würzburg U.Hennrich N, Orth HD, Lang H, (1977), Quantitative determina- tion of creatinekinase isoenzyme catalytic concentration in serum using immun-eological methods. J clin chem clin Biochem, 15:131 - 7.

Yuan JM, Sun C, Butler LM, (2011), Tea and cancer prevention: epidemiol - ogical studies. Pharmacol Res; 64 (2): 123 - 35.

Yilmaz Y., (2003), Novel uses of catechins in foods, biochemical and biophysical research communications. 304 (4):650 654.

Zhou B., Wul M., Li M (2005), Evidence for $\alpha$-tocopherol regeneration reaction of green tea polyphenols in SDS micelles, Free radical biology and medicine, 38:78 - 84 . 